\title{
Does Cocaine Use Increase Medication Noncompliance in Bipolar Disorders? A United States Nationwide Inpatient Cross-Sectional Study
}

Gibson O. Anugwom ${ }^{1,2}$, Adeolu O. Oladunjoye ${ }^{3,4}$, Tajudeen O. Basiru ${ }^{5}$, Egbebalakhamen Osa ${ }^{6}$, David Otuada $^{7}$, Victoria Olateju 8,9 , Solomon Babalola ${ }^{10}$, Olubunmi Oladunjoye ${ }^{11}$, Maria Ruiza Yee ${ }^{12,}, 13,7$, Eduardo D. Espiridion 12, 14, 15, 16, 7

1. Psychiatry and Behavioral Sciences, West Oaks Behavioral Hospital, Houston, USA 2. Psychiatry and Behavioral Sciences, Houston Behavioral Healthcare Hospital, Houston, USA 3. Psychiatry, Baylor College of Medicine, Houston, USA 4. Medical Critical Care, Boston Children's Hospital, Boston, USA 5. Developmental Behavioral Pediatrics, Dell Children's Medical Center, Austin, USA 6. Psychiatry, Essen Health Care, New York, USA 7. Psychiatry, Reading Hospital Tower Health, West Reading, USA 8. Internal Medicine, Washington Adventist University, Takoma Park, USA 9. Internal Medicine, Rockville Medical Care, Rockville, USA 10. Psychiatry, University of Texas Health Science Center at Houston, Houston, USA 11. Internal Medicine, Reading Hospital Tower Health, West Reading, USA 12. Psychiatry, Drexel University College of Medicine, Philadelphia, USA 13. Psychiatry, Philadelphia Collge of Osteopathic Medicine, Philadelphia, USA 14. Psychiatry, West Virginia School of Osteopathic Medicine, Lewisburg, USA 15. Psychiatry, West Virginia University School of Medicine, Martinsburg, USA 16. Psychiatry, Philadelphia College of Osteopathic Medicine, Philadelphia, USA

Corresponding author: Eduardo D. Espiridion, edjen19meg@gmail.com

\section{Abstract}

\section{Introduction}

Medication noncompliance among bipolar disorder (BD) is often linked with comorbid substance use disorders. This study aims to investigate cocaine use (CU) association with medication noncompliance in hospitalized BD patients.

\section{Methods}

Using data on 266,303 BD hospitalizations between 2010-2014 from the US Nationwide Inpatient Sample database, we obtained medication noncompliance rates stratified by demographics and cocaine use. Logistic regression was used to evaluate factors associated with medication noncompliance.

\section{Results}

Overall mean age, the prevalence of CU, and medication noncompliance were $41.58(+0.11)$ years, $8.34 \%$, and $16.08 \%$, respectively. More than half of BD patients with comorbid CU were between $40-64$ years (54.4\%), while more male patients with BD were in the CU group (53.9\%). With univariable logistic regression, CU (odds ratio [OR]: 1.77, 95\% CI: 1.66-1.88) increased the odds of medication noncompliance

Review began 07/13/2021 Review ended 07/17/2021 Published 07/28/2021

\section{() Copyright 2021}

Anugwom et al. This is an open access article distributed under the terms of the Creative Commons Attribution License CC-BY 4.0., which permits unrestricted use, distribution, and reproduction in any medium, provided the original author and source are credited. among BD patients, and after adjusting for other variables there was sustained increased odds (adjusted odds ratio [aOR]: $1.40,95 \%$ CI: $1.32-1.50$ ).

\section{Conclusion}

This study showed that CU is associated with medication noncompliance among hospitalized BD patients. This highlights the importance of addressing CU among BD patients. Given the possible association of CU with medication noncompliance among BD patients, collaborative work between general adult psychiatry and addiction services is imperative in improving the management outcome of BD patients with comorbid CU.

Categories: Psychiatry

Keywords: bipolar disorder, cocaine use, medication noncompliance, medication adherence, hospitalization

\section{Introduction}

Bipolar disorder (BD) is a serious mental health condition characterized by alternating episodes of mood swings, including manic and depressed episodes. Its exact cause is unknown. Bipolar disorder affects over $1 \%$ of the global population and $2.8 \%$ of the US population. BD type I affects men and women equally, while BD type II affects more women than men [1, 2]. Considerable effort has been expended in the development of pharmacological and nonpharmacological management of $\mathrm{BD}$, which has led to the use of medications such as lithium, antipsychotics, anticonvulsants, and newer treatment modalities like ketamine therapy and 
transcranial magnetic stimulation (TMS). These successes have been met with challenges, which in many ways, have limited the treatment outcomes. One of these challenges is medication noncompliance [3]. In comparison with other psychiatric pathologies, BD has one of the highest reported rates of medication noncompliance [4].

Factors associated with medication noncompliance in BD patients include adverse effects of medication, complex medication regimens, negative patient attitude to medications, poor insight, rapid cycling BD, comorbid substance misuse, and poor therapeutic alliance [5]. Medication noncompliance in BD patients carries a high risk of relapse due to the chronic and episodic nature of the illness [5].

Substance use disorder comorbidity is more common with BD than other psychiatric illnesses [6]. Patients with BD and comorbid substance use disorders have been found to experience an extensive array of psychopathological issues that are not commonly found in BD patients without co-diagnoses of substance use disorders [6]. Other studies have also identified medication noncompliance as a significant concern in BD patients with a current or previous history of substance use disorder [7]. For instance, a study by Montes et al. reported a significant association of medication nonadherence with substance use in BD patients [8]. In addition, Manwani et al. compared BD patients with and without comorbid substance use. They found a lower compliance rate in those with comorbid substance use [9]. However, to the best of our knowledge, no study has assessed the relationship of medication noncompliance with CU in BD patients using a large nationally representative database like the National Nationwide Inpatient Sample (NIS) database.

\section{Materials And Methods Study design and data sources}

We conducted a retrospective study based on the NIS data administered by the Agency for Healthcare Research and Quality, a part of the Health Care Cost and Utilization Project (HCUP) [10]. The NIS is the largest epidemiological database involving inpatient data. We analyzed all adult admissions (18 years and above) from January 1, 2010, to December 31, 2014. International Classification of Diseases Ninth Revision Clinical Modification (ICD-9-CM) was derived from 25-30 diagnoses columns which were used to identify the study population. International Classification of Diseases Tenth Revision codes were not used because they were introduced in 2015. Since the database is de-identified and publicly available, ethical clearance or Institutional Review Board approval was unnecessary. The data used in this study can be accessed from the US Department of Health and Human Services website.

\section{Study population and characterization of variables}

We included 266,303 inpatient hospitalizations (ages 18 and above) from the NIS database with a primary ICD-9 diagnosis of bipolar disorders (296.XX) (Table1). We identified ICD-9 diagnosis codes for cocaine use (CU) and other substance use disorders (Table 1). We also identified patients based on medication noncompliance using ICD-9 code: V15.81.

\section{Patient demographics and other variables}

Patient-level characteristics from the database included age (sub-divided into 18-24, 25-39, 40-64, and $65+$ years), race (white, black, and others), primary insurance payer (government, private, self-pay, and others), zip code-based annual median household income (divided into four quartiles), and regions of the US (northeast, south, midwest/north-central, and west). Other variables extracted from the database include substance use (cocaine, cannabis, stimulants, alcohol, hallucinogens) and medication compliance.

\section{Statistical analysis}

The prevalence of medication non-compliance and CU were identified among BD patients. We used bivariate analysis to compare demographics and substance use disorders in patients with BD by medication noncompliance. Multivariable logistic regression analyses adjusted for demographics were used to evaluate the factors related to medication noncompliance in BD patients. STATA version 15.0 (College Station, TX) was used for all statistical analyses. We used a p-value of $<0.05$ and a $95 \%$ confidence interval (CI). 


\section{Cureus}

\begin{tabular}{|c|c|}
\hline Diagnosis & ICD-9 diagnostic code \\
\hline Alcohol & 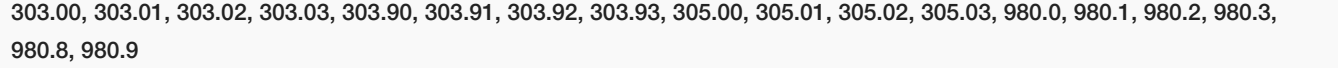 \\
\hline $\begin{array}{l}\text { Sedative- } \\
\text { hypnotic }\end{array}$ & $\begin{array}{l}\text { 304.10, 304.11, 304.13, 305.40, 305.41, 305.42, 305.43, 967.0, 967.1, 967.2, 967.3, 967.4, 967.5, 967.6, 967.8, 967.9, 969.4, } \\
\text { E851, E852.0, E852.1, E852.2, E852.3, E852.4, E852.5, E852.8, E852.9, E853.0, E853.1, E853.2, E853.8, E853.9, E937.0, E937.1, } \\
\text { E937.2, E937.3, E937.4, E937.4, E937.5, E937.6, E937.7, E937.8, E937.9 }\end{array}$ \\
\hline Cocaine & $304.20,304.22,304.23,305.60,305.61,305.62,305.63,970.81,970.89$ \\
\hline Stimulant & $304.00,304.41,304.42,304.43,305.70,305.71,305.72,305.73,969.6,970.0,970.1,970.9$, E854.2, E854.3, E854.9 \\
\hline Hallucinogen & 304.50, 304.51, 304.52, 304.53, 305.30, 305.31, 305.32, 305.53, E854.1, E855.5, E855.6, E855.8, E855.9 \\
\hline Cannabis & $304.30,304.31,304.32,305.20,305.21,305.22$ \\
\hline $\begin{array}{l}\text { Bipolar } \\
\text { disorder }\end{array}$ & $\begin{array}{l}\text { 296.40, 296.41, 296.42, 296.43, 296.44, 296.50, 296.51, 296.52, 296.53, 296.54, 296.60, 296.61, 296.62, 296.63, 296.64, 296.7, } \\
296.80,296.89\end{array}$ \\
\hline $\begin{array}{l}\text { Medication } \\
\text { noncompliance }\end{array}$ & V15.81 \\
\hline
\end{tabular}

\section{TABLE 1: ICD-9 diagnostic codes}

ICD-9: International Classification of Diseases Nine

\section{Results}

A total of 266,303 hospitalizations with BD were analyzed from 2010 to 2014, with an overall mean patient age of $41.58 \pm 0.11$ years. In this population, the prevalence of $\mathrm{CU}$ was $8.34 \%$, while that of medication noncompliance was $16.08 \%$. They were subclassed based on CU with a mean age of $40.33 \pm 0.07$ years in the CU group (Table 2). More than half of the BD patients in the CU group were between the ages of 40-64 years (54.4\%).

\begin{tabular}{|c|c|c|c|c|}
\hline Name & Overall $(n=266,303)$ & Non-CU $(n=244,080)$ & CU $(n=22,223)$ & P Value \\
\hline Mean Age $( \pm S E)$ & $41.58 \pm 0.11$ & $41.70 \pm 0.03$ & $40.33 \pm 0.07$ & $<0.001$ \\
\hline \multicolumn{5}{|l|}{ Age, years } \\
\hline $18-24$ & 14.5 & 15.1 & 8.2 & \\
\hline $25-39$ & 32.8 & 32.4 & 36.8 & \\
\hline $40-64$ & 45.2 & 44.4 & 54.4 & \\
\hline$\geq 65$ & 7.5 & 8.1 & 0.6 & $<0.001$ \\
\hline \multicolumn{5}{|l|}{ Sex, \% } \\
\hline Female & 56.6 & 57.6 & 46.1 & \\
\hline Male & 43.4 & 42.4 & 53.9 & $<0.001$ \\
\hline \multicolumn{5}{|l|}{ Race, \% } \\
\hline White & 72.9 & 74.5 & 55.8 & \\
\hline Black & 14.8 & 13.3 & 31.7 & \\
\hline Others & 12.3 & 12.2 & 12.5 & $<0.001$ \\
\hline \multicolumn{5}{|l|}{ Substance use disorder } \\
\hline Cannabis Use & 15.1 & 13.4 & 33.0 & $<0.001$ \\
\hline Stimulant & 3.2 & 2.9 & 6.7 & $<0.001$ \\
\hline Hallucinogen & 0.2 & 0.2 & 1.0 & $<0.001$ \\
\hline
\end{tabular}




\section{Cureus}

$\begin{array}{lllll}\text { Alcohol Use } & 22.3 & 20.0 & 46.7 & <0.001 \\ \text { Sedative } & 4.0 & 3.8 & 7.1 & <0.001\end{array}$

Income, \%

First quartile 32

Second quartile

Third quartile

22.4

22.8

18.8

Fourth quartile

18.3

18.7

14.3

$<0.001$

Insurance, \%

Government

60.3

Private

Self- Pay

Others

Region, \%

$\begin{array}{ll}\text { North East } & 22.3 \\ \text { Mid-West/North Central } & 27.7 \\ \text { South } & 36.3\end{array}$

West

Urban non-teaching

Urban teaching

Hospital Teaching Status, \%

Rural
25.1

8.7

5.9
59.6

67.2

26.0

15.6

8.5

11.0

5.9

6.2

$<0.001$
26.2

27.6

37.8

8.4

$<0.001$

\section{TABLE 2: Baseline and Characteristics of Bipolar Disorder Inpatients by Cocaine Use}

n: sample number; SE: Standard error; \%: percentage; CU: Cocaine Use

Table 2 describes the demographic and clinical characteristics of hospitalizations among BD patients by CU. More females were in the overall population and the non-CU group ( $56.6 \%$ and $57.6 \%$, respectively), while more males were in the $\mathrm{CU}$ group (53.9\%). The population of patient hospitalizations was predominantly white across the board, with an overall proportion of $72.9 \%$. Comorbid substance use among CU patients varied across the population, with alcohol use being the predominant substance $(46.7 \%)$ followed by cannabis use (33.0\%) and sedatives (7.1\%). Insurance coverage varied, with government insurance (Medicare and Medicaid) being the predominant coverage (60.3\%), followed by private insurance $(26.6 \%)$ and other types of insurance. About $36.3 \%$ of the patients were from the southern part of the country, and $32.6 \%$ were from areas with a national average income below the 25 th percentile.

\section{Factors associated with medication noncompliance in hospitalized bipolar disorder patients}

Table 3 describes the demographic and clinical characteristics of hospitalizations among BD patients by medication noncompliance. There was a significant difference between the characteristics of the medication noncompliance group and those that were medication compliant in terms of age, gender, race, comorbid substance use, income, insurance type hospital region, and hospital teaching status $(\mathrm{p}<0.001)$.

\begin{tabular}{|l|l|l|l|}
\hline Name & Overall $(n=266,303)$ & Non-compliance $(n=42,823)$ & Compliance $(n=223,480)$ \\
\hline Mean Age $( \pm$ SE) & $41.58 \pm 0.11$ & $41.34 \pm 0.07$ & $41.63 \pm 0.03$ \\
\hline
\end{tabular}

Age, years 


\section{Cureus}

$\begin{array}{llll}18-24 & 14.6 & 14.0 & 14.6 \\ 25-39 & 32.8 & 32.9 & 32.8 \\ 40-64 & 45.3 & 47.0 & 44.9 \\ \geq 65 & 7.4 & 6.1 & 7.7\end{array}$

14.6

2.8

44.9

7.7

$<0.001$

Sex

Female

56.6

50.8

57.8

42.2

$<0.001$

Race, \%

\section{White}

72.9

60.7

75.3

Black

14.8

Others

12.3

25.2

14.1

20.1

12.6

3.5

0.3

25.9

Alcohol Use

22.2

4.0

3.5

Income, \%

First quartile
Second quartile
Third quartile
Fourth quartile

32.6

26.6

22.4

18.3

Insurance, \%

Government

Private

Self- Pay

Others

Region, \%

North East

Mid-West/North Central

22.3

27.7

South

36.3

West

13.7

Hospital Teaching Status, \%

Rural

Urban non-teaching

Urban teaching
10.8

40.8

48.4
35.2

24.5

21.5

18.8

67.0

18.9

8.7

5.4

27.8

26.4

33.0

12.8

7.7

39.3

53.0
12.8

11.9

$<0.001$

14.0

$<0.001$

7.6

3.2

0.2

21.6

4.1

$<0.001$

0.032

0.008

$<0.001$

0.003

32.2

27.0

22.6

18.2

$<0.001$

59.0

26.3

8.7

6.0

$<0.001$

21.2

28.0

37.0

13.8

$<0.001$

11.4

41.0

47.6

TABLE 3: Baseline and clinical characteristics of Bipolar Disorders inpatients by Medication Compliance 


\section{Cureus}

With univariate analysis, the following factors were associated with medication noncompliance: ages 25-39 years compared to ages $18-24$ years (OR: 1.09, 95\% CI: 1.04-1.14, $\mathrm{p}<0.001$ ), Blacks compared to the white race (OR: $2.44,95 \%$ CI: $2.18-2.72$, p $<0.001$ ), comorbid cocaine use compared to nonuse (OR: $1.77,95 \% \mathrm{CI}$ : $1.66-1.88, \mathrm{p}<0.001$ ) (Table 4). Females were at reduced odds of medication noncompliance compared to males (OR: 0.75, 95\% CI: 0.73-0.78, $\mathrm{p}<0.001$ ). After adjusting for other covariates using multivariate analysis, there remained a statistically significant association of medication noncompliance in BD hospitalizations and comorbid cocaine use (OR: 1.41, 95\% CI: 1.32-1.50; p $<0.001$ ) (Table 4). Blacks compared to whites (OR: 2.22, 95\% CI: 1.99-2.47), ages 40-64 years compared to 18 - 24 years (OR: 1.05 , 95\% CI: 1.00 1.10 ) and urban centers compared to rural centers (urban nonteaching (OR: 1.35, 95\%CI: 1.15-1.59); urban teaching (OR: 1.43 , 95\%CI: 1.23-1.65; $\mathrm{p}<0.001$ ) also remained statistically significant.

\begin{tabular}{|c|c|c|c|c|}
\hline Name & Univariate analysis (Crude OR) & P-Value & Multivariate analysis (Adjusted OR) & P-Value \\
\hline Mean Age ( \pm SE) & $1.00(1.00-1.00)$ & 0.022 & & \\
\hline \multicolumn{5}{|l|}{ Age, years } \\
\hline $18-24$ & Ref & & & \\
\hline $25-39$ & $1.05(1.00-1.09)$ & 0.029 & $1.01(0.97-1.06)$ & 0.567 \\
\hline $40-64$ & $1.09(1.04-1.14)$ & $<0.001$ & $1.05(1.01-1.10)$ & 0.039 \\
\hline$\geq 65$ & $0.83(0.78-0.89)$ & $<0.001$ & $0.86(0.80-0.93)$ & $<0.001$ \\
\hline \multicolumn{5}{|l|}{ Sex } \\
\hline Male & Ref & & & \\
\hline Female & $0.75(0.73-0.78)$ & $<0.001$ & $0.78(0.76-0.81)$ & $<0.001$ \\
\hline \multicolumn{5}{|l|}{ Race, \% } \\
\hline White & Ref & & & \\
\hline Black & $2.44(2.18-2.72)$ & $<0.001$ & $2.22(1.99-2.47)$ & $<0.001$ \\
\hline Others & $1.47(1.36-1.59)$ & $<0.001$ & $1.37(1.27-1.48)$ & $<0.001$ \\
\hline \multicolumn{5}{|l|}{ Substance use disorder } \\
\hline Cocaine Use & $1.77(1.66-1.88)$ & $<0.001$ & $1.40(1.32-1.50)$ & $<0.001$ \\
\hline \multicolumn{5}{|l|}{ Income, \% } \\
\hline First quartile & Ref & & & \\
\hline Second quartile & $0.83(0.78-0.88)$ & $<0.001$ & $0.96(0.91-1.02)$ & 0.208 \\
\hline Third quartile & $0.87(0.80-0.93)$ & $<0.001$ & $0.99(0.92-1.07)$ & 0.884 \\
\hline Fourth quartile & $0.94(0.85-1.04)$ & 0.251 & $1.11(1.00-1.23)$ & 0.046 \\
\hline \multicolumn{5}{|l|}{ Insurance, \% } \\
\hline Government & Ref & & & \\
\hline Private & $0.63(0.59-0.67)$ & $<0.001$ & $0.67(0.64-0.71)$ & $<0.001$ \\
\hline Self- Pay & $0.88(0.80-0.97)$ & 0.009 & $0.89(0.81-0.98)$ & 0.018 \\
\hline Others & $0.79(0.72-0.86)$ & $<0.001$ & $0.83(0.75-0.91)$ & $<0.001$ \\
\hline \multicolumn{5}{|l|}{ Region, \% } \\
\hline North East & Ref & & & \\
\hline Mid-West/North Central & $0.72(0.60-0.86)$ & $<0.001$ & $0.77(0.64-0.91)$ & 0.002 \\
\hline South & $0.68(0.59-0.78)$ & $<0.001$ & $0.72(0.62-0.82)$ & $<0.001$ \\
\hline West & $0.70(0.59-0.85)$ & $<0.001$ & $0.77(0.64-0.93)$ & 0.008 \\
\hline
\end{tabular}




\section{Cureus}

Hospital Teaching Status, \%

Rural

Ref

Urban non-teaching

$1.42(1.21-1.67)$

$<0.001$

$1.35(1.15-1.59)$

$<0.001$

Urban teaching

$1.65(1.42-1.88)$

$<0.001 \quad 1.43(1.23-1.65)$

$<0.001$

TABLE 4: Factors associated with medication noncompliance in hospitalized patients with bipolar disorders

SE: Standard error; \%: percentage; ref: reference

\section{Discussion}

The findings in this study show that the medication noncompliance rate among hospitalized BD patients was $16 \%$. While few studies have examined medication compliance among hospitalized BD patients, medication noncompliance rates vary considerably across the literature [11], with most studies reporting over $40 \%$ nonadherence rates among BD patients [12]. A study that asked European psychiatrists about medication non-compliance among BD patients found an estimated rate of 57\% [13]. An article published in the World Journal of Psychiatry supports the high variability in the reported adherence rates because these rates depend on the settings where the studies were conducted. Some specialized settings, such as hospitalized patients, as in our study, may report very low rates of medication noncompliance $[9,14]$, while others may report higher rates [3].

In the bivariate analysis (Table 3), BD patients that used cocaine and other substances were significantly more likely to be non-adherent with medication $(\mathrm{p}<0.05)$. In the logistic regression analysis, cocaine use was significantly associated with an increased risk of medication noncompliance after adjusting for other factors (aOR: 1.40, 95\% CI: 1.32-1.50, p <0.001). Few studies have examined the association of CU with medication noncompliance among BD patients. However, the relationship between substance use and BD is well established in the literature [5]. Many studies have found substance abuse (including cocaine) to be significantly associated with a higher risk of medication noncompliance in BD patients $[15,16]$. The current study is unique in that it examines the association of CU with medication noncompliance in hospitalized BD patients using nationally representative data.

We found that the use of other substances (cannabis, stimulants, hallucinogens, alcohol, and sedatives) by $\mathrm{BD}$ patients with comorbid CU was about twice the rate of use of similar substances in BD patients without comorbid CU. This is an expected finding because people that use one substance are at higher risk for polysubstance use, and other studies have shown the association of polysubstance abuse with many psychiatric illnesses, including BD [17]. The lifetime prevalence of comorbidity of any BD with any substance use disorder is said to be over $47 \%$, and up to $60 \%$ for bipolar I disorder [18]. The relationship between BD and substance use is suggested by multiple research to be bidirectional [19].

In our study, $31.7 \%$ of non-CU BD patients were in the lower-income group (first quartile), compared to over $40 \%$ of BD patients with comorbid CU. In addition, while $67.2 \%$ of the CU group had government insurance, the proportion of non-cocaine users with government insurance was less than $60 \%$. These findings suggest that BD patients who use cocaine are likely to be financially constrained than those who do not use cocaine. This may also explain why more patients in this group may prefer to use government insurance as it is more affordable than private insurance. There is also a possibility of greater use of government resources among those that use cocaine than those that do not use cocaine. Although there are limited studies on the relationship between personal finances and substance use in BD patients, these findings seem to agree with some studies that suggest an adverse relationship and overall increased consumption of public resources among substance use patients $[20,21]$.

We found older age (age 65 years and older) to be significantly associated with a reduced risk of medication noncompliance compared to other age groups after controlling for other factors ( $95 \% \mathrm{CI}=0.78-0.89$, p-value $<0.001$ ). This is similar to findings from studies that examined factors associated with medication noncompliance. For instance, Sajatovic et al. and Baldessarini et al. reported increased odds of medication noncompliance in younger age groups compared to older age groups [22, 23]. It is noteworthy that our study did not show a significant association between younger age groups and medication noncompliance among BD patients. Female gender was found to be associated with a lower risk of noncompliance in this study compared to male gender after controlling for other factors using multivariate analysis OR (95\% CI) 0.78 (0.76-0.81), p-value $<0.001$. Many published studies did not find a statistically significant association between gender and medication noncompliance among BD patients [24, 25]. Of note, in the current study CU patients were also more likely to be male. Sajatovic et al. found that men with high masculinity index were four times more likely to be noncompliant with medication than female gender or males without high 
From our study, race played a significant factor in medication noncompliance. While only $14.8 \%$ of patients in our study were Black, the proportion of Black patients among those not compliant was over $25 \%$. In the multivariate analysis, we found that being Black and being from races other than white were associated with increased odds of medication noncompliance OR(95\%CI) 2.44 (2.18-2.72), p<0.001 and 1.47 (1.36-1.59) respectively) which supports findings from previous studies [26, 27]. Sajatovic et al. that evaluated factors that influence medication nonadherence among a highly nonadherent group found that minorities such as Blacks were disproportionately represented [28].

Several poor outcomes have been linked with medication noncompliance in BD patients, including reduced treatment effectiveness, re-hospitalization, poor quality of life, relapse of symptoms, increased comorbid medical conditions, wastage of health care resources, increased suicide rates, and decreased likelihood of illness remission [29]. Some of the factors associated with medication noncompliance in these patients include adverse effects of medication, complex medication regimens, negative patient attitude to medications, poor insight, rapid cycling BD, comorbid substance misuse, and poor therapeutic alliance [5]. Among these factors, substance use disorder is estimated to be hugely responsible for most of the adverse outcomes in these patients [30].

A strength of this study is the use of large nationally representative data, which increases the power of the study and allows the generalization of findings to other patients in similar settings. However, one of the limitations in this study includes the fact that data of hospitalized patients were used, thereby limiting generalization of findings to the general population. Another limitation is the possibility of over- or underestimation of rates in using the NIS data because the data is derived from ICD codes that are vulnerable to administrative coding errors.

\section{Conclusions}

Medication noncompliance in BD treatment is associated with multiple detrimental effects during BD management. The report that BD patients who have a comorbid CU are more likely to be medication noncompliance highlights the importance of addressing substance use and BD. A better understanding of strategies necessary to address these concerns might be a step in the right direction in caring for BD patients.

Given the possible association of CU and medication noncompliance among BD patients, collaborative work between general adult psychiatry and addiction services is imperative in improving the management outcome of BD patients with comorbid CU.

\section{Additional Information}

\section{Disclosures}

Human subjects: Consent was obtained or waived by all participants in this study. Animal subjects: All authors have confirmed that this study did not involve animal subjects or tissue. Conflicts of interest: In compliance with the ICMJE uniform disclosure form, all authors declare the following: Payment/services info: All authors have declared that no financial support was received from any organization for the submitted work. Financial relationships: All authors have declared that they have no financial relationships at present or within the previous three years with any organizations that might have an interest in the submitted work. Other relationships: All authors have declared that there are no other relationships or activities that could appear to have influenced the submitted work.

\section{References}

1. Müller JK, Leweke FM: Bipolar disorder: clinical overview. Med Monatsschr Pharm. 2016, 39:363-9.

2. Harvard Medical School: national comorbidity survey. (2017). Accessed: May 11, 2021: https://www.hcp.med.harvard.edu/ncs/..

3. Chakrabarti S: Treatment-adherence in bipolar disorder: A patient-centred approach . World J Psychiatry 2016, 6:399-409. 10.5498/wip.v6.i4.399

4. Lingam R, Scott J: Treatment non-adherence in affective disorders . Acta Psychiatr Scand. 2002, 105:164-72. 10.1034/j.1600-0447.2002.1r084.x

5. Jawad I, Watson S, Haddad PM, Talbot PS, McAllister-Williams RH: Medication nonadherence in bipolar disorder: a narrative review. Ther Adv Psychopharmacol. 2018, 8:349-63. 10.1177/2045125318804364

6. Goldberg JF: Bipolar disorder with comorbid substance abuse: diagnosis, prognosis, and treatment . J Psychiatr Pract. 2001, 7:109-22. 10.1097/00131746-200103000-00004

7. Maarbjerg K, Aagaard J, Vestergaard P: Adherence to lithium prophylaxis: I. Clinical predictors and patient's reasons for nonadherence. Pharmacopsychiatry. 1988, 21:121-5. 10.1055/s-2007-1014662

8. Montes JM, Maurino J, de Dios C, Medina E: Suboptimal treatment adherence in bipolar disorder: impact on clinical outcomes and functioning. Patient Prefer Adherence. 2013, 7:89-94. 10.2147/PPA.S39290

9. Manwani SG, Szilagyi KA, Zablotsky B, Hennen J, Griffin ML, Weiss RD: Adherence to pharmacotherapy in bipolar disorder patients with and without co-occurring substance use disorders. J Clin Psychiatry. 2007, 68:1172-6. 10.4088/jcp.v68n0802 
10. US Department of Health and Human Services: HCUP-US NIS overview . (2021). Accessed: May 11, 2021: https://www.hcup-us.ahrq.gov/nisoverview.jsp.

11. Pompili M, Serafini G, Del Casale A, et al.: Improving adherence in mood disorders: the struggle against relapse, recurrence and suicide risk. Expert Rev Neurother. 2009, 9:985-1004. 10.1586/ern.09.62

12. Sajatovic M, Elhaj O, Youngstrom EA, Bilali SR, Rapport DJ, Ganocy SJ, Calabrese JR: Treatment adherence in individuals with rapid cycling bipolar disorder: results from a clinical-trial setting. J Clin Psychopharmacol. 2007, 27:412-4. 10.1097/01.jcp.0000280310.50871.ff

13. Vieta E, Azorin JM, Bauer M, Frangou S, Perugi G, Martinez G, Schreiner A: Psychiatrists' perceptions of potential reasons for non- and partial adherence to medication: results of a survey in bipolar disorder from eight European countries. J Affect Disord. 2012, 143:125-30. 10.1016/j.jad.2012.05.041

14. Sylvia LG, Reilly-Harrington NA, Leon AC, et al.: Medication adherence in a comparative effectiveness trial for bipolar disorder. Acta Psychiatr Scand. 2014, 129:359-65. 10.1111/acps.12202

15. Jónsdóttir H, Opjordsmoen S, Birkenaes AB, et al.: Predictors of medication adherence in patients with schizophrenia and bipolar disorder. Acta Psychiatr Scand. 2013, 127:23-33. 10.1111/j.16000447.2012.01911.x

16. Lang K, Korn J, Muser E, Choi JC, Abouzaid S, Menzin J: Predictors of medication nonadherence and hospitalization in Medicaid patients with bipolar I disorder given long-acting or oral antipsychotics. J Med Econ. 2011, 14:217-26. 10.3111/13696998.2011.562265

17. Bhalla IP, Stefanovics EA, Rosenheck RA: Clinical epidemiology of single versus multiple substance use disorders: polysubstance use disorder. Med Care. 2017, 55 Suppl 9 Suppl 2:S24-32. 10.1097/MLR.0000000000000731

18. Pettinati HM, O'Brien CP, Dundon WD: Current status of co-occurring mood and substance use disorders: a new therapeutic target. Am J Psychiatry. 2013, 170:23-30. 10.1176/appi.ajp.2012.12010112

19. Biederman J, Mick E, Faraone SV, Spencer T, Wilens TE, Wozniak J: Pediatric mania: a developmental subtype of bipolar disorder?. Biol Psychiatry. 2000, 48:458-66. 10.1016/s0006-3223(00)00911-2

20. Peirce RS, Frone MR, Russell M, Cooper ML: Relationship of financial strain and psychosocial resources to alcohol use and abuse: the mediating role of negative affect and drinking motives. J Health Soc Behav. 1994, 35:291-308. 10.2307/2137211

21. Klenk L, von Rütte C, Henssler JF, Sauter TC, Hautz WE, Exadaktylos AK, Müller M: Resource consumption of multi-substance users in the emergency room: A neglected patient group. PLoS One. 2019, 14:e0223118. 10.1371/journal.pone.0223118

22. Sajatovic M, Valenstein M, Blow FC, Ganoczy D, Ignacio RV: Treatment adherence with antipsychotic medications in bipolar disorder. Bipolar Disord. 2006, 8:232-41. 10.1111/j.1399-5618.2006.00314.x

23. Baldessarini RJ, Perry R, Pike J: Factors associated with treatment nonadherence among US bipolar disorder patients. Hum Psychopharmacol. 2008, 23:95-105. 10.1002/hup.908

24. Sajatovic M, Bauer MS, Kilbourne AM, Vertrees JE, Williford W: Self-reported medication treatment adherence among veterans with bipolar disorder. Psychiatr Serv. 2006, 57:56-62. 10.1176/appi.ps.57.1.56

25. Sajatovic M, Micula-Gondek W, Tatsuoka C, Bialko C: The relationship of gender and gender identity to treatment adherence among individuals with bipolar disorder. Gend Med. 2011, 8:261-8. 10.1016/j.genm.2011.06.002

26. García S, Martínez-Cengotitabengoa M, López-Zurbano S, Zorrilla I, López P, Vieta E, González-Pinto A: Adherence to antipsychotic medication in bipolar disorder and schizophrenic patients: A systematic review . J Clin Psychopharmacol. 2016, 36:355-71. 10.1097/JCP.0000000000000523

27. Johnson FR, Ozdemir S, Manjunath R, Hauber AB, Burch SP, Thompson TR: Factors that affect adherence to bipolar disorder treatments: a stated-preference approach. Med Care. 2007, 45:545-52. 10.1097/MLR.0b013e318040ad90

28. Sajatovic M, Levin J, Fuentes-Casiano E, Cassidy KA, Tatsuoka C, Jenkins JH: Illness experience and reasons for nonadherence among individuals with bipolar disorder who are poorly adherent with medication. Compr Psychiatry. 2011, 52:280-7. 10.1016/j.comppsych.2010.07.002

29. Semahegn A, Torpey K, Manu A, Assefa N, Tesfaye G, Ankomah A: Psychotropic medication non-adherence and its associated factors among patients with major psychiatric disorders: a systematic review and metaanalysis. Syst Rev. 2020, 9:17. 10.1186/s13643-020-1274-3

30. Chakrabarti S: Medication non-adherence in bipolar disorder: Review of rates, demographic and clinical predictors. World J Meta-Anal. 2017, 5:103. 10.13105/wjma.v5.i4.103 